\title{
Enraizamento de estacas de Melaleuca alternifolia submetidas a diferentes reguladores vegetais
}

\section{Rooting of Melaleuca alternifolia cuttings with different plant regulators}

\author{
Rosemeire Carvalho da Silva ${ }^{1 *}$; Marina Costacurta Antunes ${ }^{1}$; \\ Luís Fernando Roveda ${ }^{1}$; Tereza Cristina de Carvalho'; Luiz Antonio Biasi ${ }^{2}$
}

\section{Resumo}

A Melaleuca alternifolia é uma árvore da família Myrtaceae, de grande importância medicinal. Seu óleo essencial é muito utilizado tanto na medicina humana quanto na medicina veterinária, tendo grande poder antiséptico. É uma planta de difícil enraizamento no processo de estaquia. Assim, o presente trabalho teve como objetivo avaliar a eficiência de diferentes concentrações de ANA e AIB, no enraizamento de estacas de $M$. alternifolia. Foram utilizadas estacas com $10 \mathrm{~cm}$ de comprimento, submetidas ao tratamento para enraizamento com dois reguladores vegetais ANA e AIB, nas seguintes concentrações: 0 (testemunha); 1000; 2000 e $4000 \mathrm{mg} \mathrm{L}^{-1}$. Aos 97 dias foram avaliados a porcentagem de estacas enraizadas, vivas e mortas, o comprimento, o volume e a massa seca de raízes. O regulador vegetal ANA na concentração de $4000 \mathrm{mg} \mathrm{L}^{-1}$ demonstrou ser fitotóxico para as estacas de melaleuca e o uso de AIB em relação ao ANA, na concentração de $4000 \mathrm{mg} \mathrm{L}^{-1}$, proporcionou maior porcentagem de estacas enraizadas e maior comprimento radicial.

Palavras-chave: Myrtaceae, estaquia, AIB; ANA

\begin{abstract}
The Melaleuca alternifolia is a Myrtaceae tree of great medicinal importance. Its essential oil is widely used both in human and in veterinary medicine, having great antiseptic power. It is a difficult plant in the process of rooting cuttings. This study aimed to evaluate the efficacy of different concentrations of NAA and IBA on the rooting of $M$. alternifolia. Melaleuca cuttings with $10 \mathrm{~cm}$ in length were submitted to treatments with two regulators, NAA and IBA, in the following concentrations: 0 (control), 1000, 2000 and $4000 \mathrm{mg} \mathrm{L}^{-1}$. Evaluation occurred at 97 days throughout the live and dead cuttings rooted, medium length, volume and mass of roots. The growth regulator NAA at a concentration of $4000 \mathrm{mg} \mathrm{L}^{-1}$ showed to be phytotoxic to the cuttings of melaleuca; the use of IBA in comparable with NAA at concentration of $4000 \mathrm{mg} \mathrm{L}^{-1}$ provided a higher percentage of rooting and root length increases.
\end{abstract}

Key words: Myrtaceae, cutting, IBA, NAA

\footnotetext{
${ }^{1}$ Discente(s) do programa de pós-graduação em Agronomia-Produção Vegetal, Universidade Federal do Paraná, UFPR, Curitiba, PR. E-mail: rosemeirecarvalhosilva@gmail.com; marinacostacurta@hotmail.com; lfroveda@uol.com.br; tcdcarva@gmail.com ${ }^{2}$ Prof. Adjunto do Dept ${ }^{\mathrm{o}}$ de Fitotecnia e Fitossanitarismo da UFPR, Curitiba, PR. E-mail: biasi@ufpr.br *Autor para correspondência
} 


\section{Introdução}

A Melaleuca alternifolia, também conhecida como árvore de chá ou melaleuca, pertence à família das Myrtaceae. Sua distribuição geográfica ocorre predominantemente em regiões tropicais e subtropicais (SOUZA; LORENZI, 2005). Conforme relatado por Lee et al. (2002), a M. alternifolia habita zonas de água doce e pântanos ribeirinhos em três sistemas fluviais da Austrália, sendo estes os rios Clarence e Richmond, situados ao norte do Estado de New South Wales, e do rio Severn localizado no sul do Estado de Queensland.

O principal produtor da $M$. alternifolia é a Austrália, sendo os principais usuários, a América do Norte e a Europa (VIEIRA; BARBOSA; MALTHA, 2004). A M. alternifolia é utilizada para finalidade medicinal e produção de cosméticos, pela extração do óleo essencial de suas folhas. O óleo contém quantidades variadas de terpenos (pineno, terpineno e cimeno), terpinenol (terpinen-4-ol), sesquiterpenos e cineol (ALTMAN, 1989; RUSSEL; SOUTHWELL, 2002), que são os constituintes mais importantes relacionados à atividade antimicrobiana e antifúngica.

A colheita é feita pela retirada das brotações, onde toda a planta é cortada ao nível do solo, e seus ramos fragmentados antes da extração do óleo (CARSON; HAMMER; RILEY, 2006).

O óleo é extraído por destilação a vapor das folhas e ramos terminais da M. alternifolia. Uma vez condensado, o óleo claro para amarelo-pálido é separado do destilado aquoso. O rendimento do óleo é normalmente $1-2 \%$ do peso úmido do material vegetal. Alguns métodos de extração alternativos, como o uso da tecnologia de microondas tem sido considerado, mas nenhum tem sido utilizado em escala comercial (CARSON; HAMMER; RILEY, 2006).

O estabelecimento das plantas de M. alternifolia em campo é possível pelo plantio de mudas, que tem como vantagem um rápido estabelecimento. A produção de mudas pode ser feita pelo uso de estacas ou por sementes, mas ainda é um entrave para a expansão da espécie e trabalhos científicos que ajudem a esclarecer o melhor processo de propagação desta espécie são escassos. Dentre as formas de propagação, a estaquia apresenta muitas vantagens além de ser uma técnica barata e rápida (HARTMANN et al., 2002). Umas das técnicas utilizadas na estaquia para melhorar o enraizamento é a utilização de reguladores vegetais a base de auxinas sintéticas, como o ácido alfanaftalenoacético (ANA) e ácido 4 (3 indolil) butírico (AIB) (HARTMANN et al., 2002; COSTA et al., 2007).

Costa Junior, Scarpare Filho e Bastos (2003) observaram, em goiabeira, maior porcentagem de estacas enraizadas com a utilização de AIB na concentração de 2000 mg L${ }^{-1}$. Costa et al. (2007) testando diferentes concentrações de AIB em estacas de $M$. alternifolia, relataram que a concentração de $1500 \mathrm{mg} \mathrm{L}^{-1}$ apresentou melhor porcentagem de estacas enraizadas $(82,5 \%)$. Outro fator a ser observado nas estacas é o comprimento de estacas visto que Oliveira et al. (2008) observaram maior taxa de enraizamento com estacas de $10 \mathrm{~cm}$ de comprimento.

Dessa forma, o objetivo do presente trabalho foi avaliar a eficiência de diferentes concentrações de ANA e AIB, no enraizamento de estacas de $M$. alternifolia.

\section{Material e Métodos}

O trabalho foi conduzido no Departamento de Fitotecnia e Fitossanitarismo, da Universidade Federal do Paraná, em Curitiba - PR, no período de março a junho de 2010. As estacas de M. alternifolia utilizadas na pesquisa foram obtidas de ramos semilenhosos de plantas matrizes cultivadas na Estação Experimental do Canguiri da Universidade Federal do Paraná, em Pinhais-PR, sendo colhidas em 22 de março de 2010.

Foram utilizadas estacas caulinares apicais, com $10 \mathrm{~cm}$ de comprimento, sendo retiradas as pequenas 
folhas de dois terços da porção basal das estacas e mantidas intactas as folhas do terço superior (OLIVEIRA et al., 2008). Após a confecção, as estacas foram submetidas ao tratamento de desinfecção com solução de hipoclorito de sódio na concentração de $5000 \mathrm{mg} \mathrm{L^{-1 }}$ por 15 minutos, sendo na sequência lavadas em água corrente por cinco minutos e então tratadas com os reguladores vegetais ANA e AIB.

No tratamento das estacas, utilizou-se quatro concentrações de ANA e AIB, a saber: 0 (testemunha); 1000; 2000 e 4000 mg L-1. Durante o tratamento, a parte basal (aproximadamente 3 $\mathrm{cm}$ ) das estacas foram imersas na solução por dez segundos, conforme procedimento descrito por Silva et al. (2009) para estacas de camu-camu (Myrtaceae), posteriormente estas foram plantadas em tubetes $\left(53 \mathrm{~cm}^{3}\right)$ contendo substrato vermiculita de granulometria média.

As estacas foram mantidas em casa de vegetação, com irrigação de 15 segundos em intervalos de 15 minutos entre $8 \mathrm{~h}$ às $19 \mathrm{~h}$ e intervalos de 2 horas entre $19 \mathrm{~h}$ às $8 \mathrm{~h}$. Ao final de 14 semanas (97 dias) de cultivo, as estacas foram retiradas da vermiculita e avaliadas quanto: à porcentagem de estacas vivas e enraizadas, mortas e vivas não enraizadas. As raízes foram submetidas à leitura ótica com scanner e analisadas pelo programa Win Mac Rhizo ${ }$, para obtenção do volume radicial $\left(\mathrm{cm}^{3}\right)$ e comprimento médio do total de raízes $(\mathrm{cm})$. Após estas análises foi avaliada a massa seca radicial ( $\mathrm{mg})$.

Os dados obtidos foram analisados de acordo com o delineamento inteiramente casualizado, em esquema fatorial ( $2 \times 4)$, compreendendo dois reguladores vegetais, $\mathrm{ANA}$ e AIB, e quatro diferentes concentrações, 0 (testemunha), 1000, 2000 e 4000 $\mathrm{mg} \mathrm{L^{-1 }}$. Os resultados da porcentagem de estacas vivas e enraizadas, mortas e vivas não enraizadas foram transformados em arco seno $\sqrt{\mathrm{x}} / 100$; e para as demais variáveis empregou-se a transformação em $\sqrt{ } \mathrm{x}+1$; sendo os resultados apresentados em seus valores originais. Para a análise dos dados empregou-se o software ASSISTAT, versão 7.6 beta
(SILVA, 2008). Quando constatada significância pelo teste $\mathrm{F}$, as médias foram testadas, dentro de reguladores pelo teste de Tukey $(p \leq 0,01)$ e dentro de concentrações por modelos de regressão escolhendo a equação de melhor ajuste.

\section{Resultados e Discussão}

Pelos resultados apresentados na Tabela 1, foi possível observar que a porcentagem de estacas vivas não enraizadas se manteve em níveis similares de viabilidade em todas as concentrações de reguladores (ANA e AIB) testadas. No entanto, verifica-se maior porcentagem de viabilidade das estacas não enraizadas (Tabela 1), quando as concentrações de ANA e AIB foram de 1000 e 2000 $\mathrm{mg} \mathrm{L^{-1 }}$. Ao analisar a eficiência dos reguladores de crescimento AIA, ANA e AIB, para o enraizamento de Uncaria tomentosa, Vasconcelos et al. (2010) observaram resultados similares.

$\mathrm{O}$ efeito de reguladores vegetais, muitas vezes ocorre quando os tratamentos consistem em concentrações mais elevadas, como observado em Centellas et al. (1999) que avaliaram melhor porcentagem de enraizamento de macieira, nas concentrações mais altas testadas de ácido indol-3-acético (AIA). Resultados similares foram observados por Fischer et al. (2008), para o enraizamento de variedades de mirtilo, em que os melhores resultados foram obtidos nas concentrações de $8000 \mathrm{mg} \mathrm{L}^{-1}$ de AIB.

Segundo Centellas et al. (1999) há acúmulo de auxinas endógenas de origem das folhas ou gemas caulinares, fator que provavelmente contribuiu no enraizamento destas estacas. Uma vez que, a formação de raízes está relacionada com o acúmulo de auxinas endógenas, associado ao aumento da atividade metabólica do tecido (WAREING; PHILLIPS, 1981). Assim, é possível que a manutenção de apenas um terço das folhas em cada estaca, tenha interferido negativamente no enraizamento destas, pois o número de folhas remanescentes pode ter sido insuficiente para o acúmulo de auxinas endógenas nas estacas. 
Tabela 1. Dados médios de estacas semi-lenhosas de Melaleuca alternifolia vivas não enraizadas, mortas e enraizadas, submetidas a diferentes concentrações de reguladores vegetais ácido alfa-naftalenoacético (ANA) e acido 4 (3 indolil) butírico P.S. (AIB), sob diferentes concentrações.

\begin{tabular}{|c|c|c|c|c|}
\hline \multirow{3}{*}{ Regulador vegetal } & \multicolumn{4}{|c|}{ Concentracões dos reguladores vegetais em mg L-1 } \\
\hline & 0 & 1000 & 2000 & 4000 \\
\hline & \multicolumn{4}{|c|}{ Estacas vivas não enraizadas (\%) } \\
\hline ANA & $43,75 \mathrm{aA}$ & $57,50 \mathrm{aA}$ & $50,00 \mathrm{aA}$ & $47,50 \mathrm{aA}$ \\
\hline AIB & $47,50 \mathrm{aA}$ & $50,00 \mathrm{aA}$ & $48,75 \mathrm{aA}$ & $35,00 \mathrm{aA}$ \\
\hline CV $(\%)$ & \multicolumn{4}{|c|}{20,69} \\
\hline & \multicolumn{4}{|c|}{ Estacas mortas $(\%)$} \\
\hline ANA & $12,75 \mathrm{aA}$ & $12,25 \mathrm{aA}$ & $13,75 \mathrm{aA}$ & $18,75 \mathrm{aA}$ \\
\hline AIB & $12,25 \mathrm{aA}$ & $12,00 \mathrm{aA}$ & $12,25 \mathrm{aA}$ & $12,25 \mathrm{bA}$ \\
\hline $\mathrm{CV}(\%)$ & \multicolumn{4}{|c|}{56,33} \\
\hline & \multicolumn{4}{|c|}{ Estacas enraizadas (\%) } \\
\hline ANA & $52,50 \mathrm{aA}$ & $41,25 \mathrm{aA}$ & $41,00 \mathrm{aA}$ & $18,50 \mathrm{bB}$ \\
\hline AIB & $51,25 \mathrm{aA}$ & $50,00 \mathrm{aA}$ & $57,50 \mathrm{aA}$ & $62,50 \mathrm{aA}$ \\
\hline $\mathrm{CV}(\%)$ & \multicolumn{4}{|c|}{19,34} \\
\hline
\end{tabular}

Médias seguidas pela mesma letra maiúscula na linha e minúscula na coluna não diferem entre si pelo teste de Tukey (p $\leq 0,01$ ).

Fonte: Elaboração dos autores.

Ao analisar a porcentagem de estacas mortas de melaleuca (Tabela 1), o ANA apresentou valores superiores de mortalidade na maior dose (4000 $\mathrm{mg} \mathrm{L}^{-1}$ ), em relação ao AIB, bem como menor a porcentagem de estacas enraizadas. Estes resultados podem ser indicativos de maior fitotoxidez deste regulador (ANA). Independentemente das doses aplicadas de AIB não se observou diferenças estatísticas sobre a porcentagem de estacas mortas (Figura 1) e nem para estacas enraizadas (Figura 2).

Figura 1. Porcentagem de estacas mortas de Melaleuca alternifolia sob diferentes concentrações de acido alfanaftalenoacético (ANA) e ácido 4 (3 indolil) butírico (AIB).

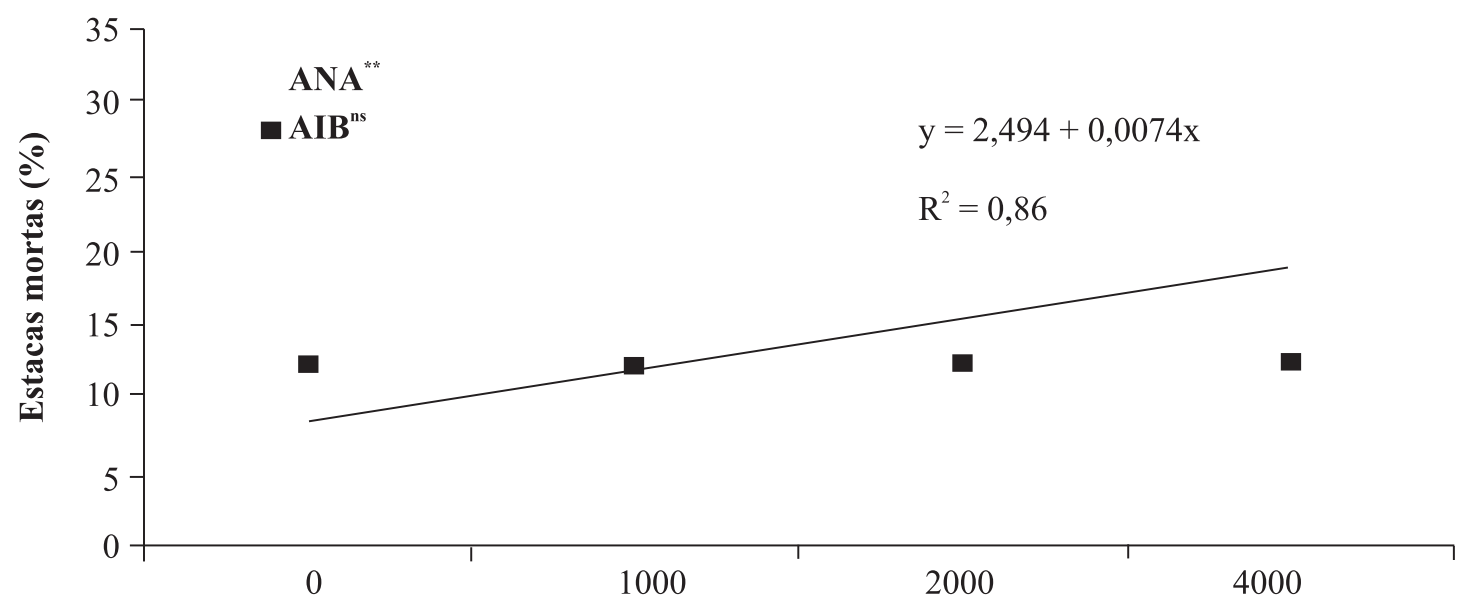

Concentrações $\left(\mathrm{mg} \mathrm{L}^{-1}\right)$

**Significativo ao nível de $1 \%$.

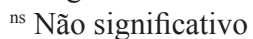

Fonte: Elaboração dos autores. 
Figura 2. Porcentagem de estacas enraizadas de Melaleuca alternifolia sob diferentes concentrações de acido alfanaftalenoacético (ANA) e ácido 4 (3 indolil) butírico (AIB).

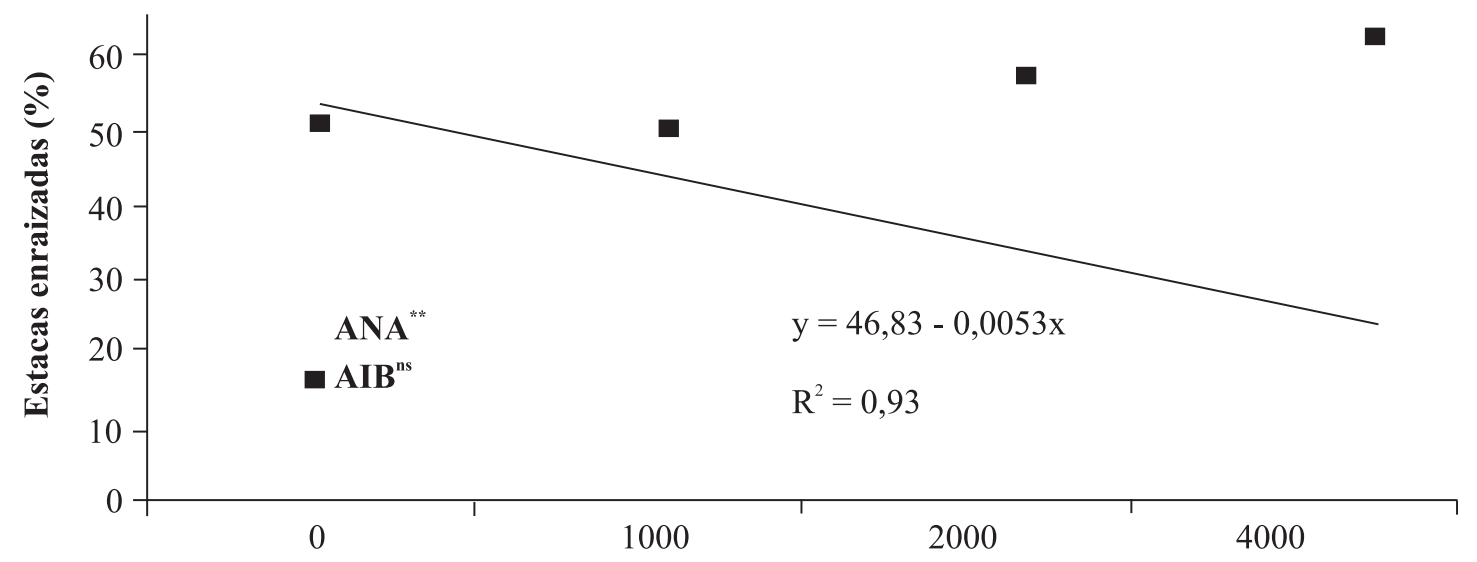

Concentrações $\left(\mathrm{mg} \mathrm{L}^{-1}\right)$

**Significativo ao nível de $1 \%$.

ns Não significativo

Fonte: Elaboração dos autores.

Verifica-se, que a maior porcentagem de mortalidade de estacas de melaleuca ocorreu para o ANA (Figura 1), quanto foram empregadas as maiores concentrações deste regulador vegetal; principalmente nas concentrações 2000 e $4000 \mathrm{mg}$ $\mathrm{L}^{-1}$. Proporcionalmente, para as estacas enraizadas (Figura 2), quanto maior foi a dose de ANA menor foram as estacas enraizadas. Esses resultados são indicativos que, a elevação da concentração do ANA induz o aumento na mortalidade de estacas de melaleuca, provavelmente em função da fitotoxicidade deste regulador vegetal. Estudos têm preconizado que o aumento da concentração de reguladores aplicados em plantas, provoca efeito estimulador de raízes até certo nível, a partir do qual, concentrações maiores têm efeito inibitório (FACHINELLO et al., 1995), ou em outros casos tóxico, como o efeito observado de ANA (Tabela 1).

Em estudo realizado por Delgado e Yuyama (2010) para o enraizamento de camu-camu (família das Myrtaceae), foi verificado que o uso de AIB na concentração de $200 \mathrm{mg} \mathrm{L}^{-1}$ proporcionou aumento considerável no enraizamento das estacas. Tais resultados sugerem estudos futuros com a utilização de diferentes concentrações deste regulador, com a adoção de concentrações reduzidas.

Ao analisar os resultados do volume radicial (Tabela 2), observou-se que as estacas tratadas com AIB, apresentaram maior volume radicial em relação às estacas tratadas com ANA, para todas as concentrações avaliadas. No entanto, ao verificar o comportamento do enraizamento destas estacas mediante o aumento da concentração, do regulador AIB, não houve diferenças significativas entre as doses testadas $(\mathrm{p} \leq 0,01)$.

Esses resultados se diferem dos apresentados por Franzon, Antunes e Roseira (2004), que não obtiveram resposta positiva no enraizamento de estacas de goibeira-serrana (Acca sellowiana Berg) ao utilizarem AIB nas concentrações de 0, 2000, 4000 e $8000 \mathrm{mg} \mathrm{L}^{-1}$, além de constatarem fitotoxidez em AIB nas estacas herbáceas, nas concentrações a partir de $4000 \mathrm{mg} \mathrm{L}^{-1}$. Os autores ainda relatam que diversas espécies da família Myrtaceae apresentam dificuldades de enraizamento, tais como jabuticabeiras e goiabeiras. No entanto, a literatura 
apresenta eficientes resultados de enraizamento de estacas de espécies desta família com o uso de reguladores vegetais, em especial com aplicação de AIB (COSTA JUNIOR; SCARPARE FILHO;

BASTOS, 2003; DELGADO; YUYAMA, 2010).

Tabela 2. Dados médios do volume radicial, comprimento de raízes e massa seca radicial de estacas semi-lenhosas de Melaleuca alternifolia, submetidas a diferentes concentrações de reguladores vegetais ácido alfa-naftalenoacético (ANA) e acido 4 (3 indolil) butírico P.S. (AIB), sob diferentes concentrações.

\begin{tabular}{|c|c|c|c|c|}
\hline \multirow{3}{*}{ Regulador vegetal } & \multicolumn{4}{|c|}{ Concentrações dos reguladores vegetais em $\mathrm{mg} \mathrm{L}^{-1}$} \\
\hline & 0 & 1000 & 2000 & 4000 \\
\hline & \multicolumn{4}{|c|}{ Volume radicial $\left(\mathrm{cm}^{3}\right)$} \\
\hline ANA & $0,13 \mathrm{bA}$ & $0,15 \mathrm{bA}$ & $0,21 \mathrm{bA}$ & $0,13 \mathrm{bA}$ \\
\hline AIB & $0,30 \mathrm{aA}$ & $0,32 \mathrm{aA}$ & $0,40 \mathrm{aA}$ & $0,37 \mathrm{aA}$ \\
\hline \multirow[t]{2}{*}{$\mathrm{CV}(\%)$} & \multicolumn{4}{|c|}{3,88} \\
\hline & \multicolumn{4}{|c|}{ Comprimento de raízes $(\mathrm{cm})$} \\
\hline ANA & $33,13 \mathrm{bA}$ & $28,52 \mathrm{aA}$ & $40,85 \mathrm{aA}$ & $16,38 \mathrm{bA}$ \\
\hline AIB & $69,25 \mathrm{aA}$ & $41,16 \mathrm{aA}$ & $60,81 \mathrm{aA}$ & $57,71 \mathrm{aA}$ \\
\hline $\mathrm{CV}(\%)$ & \multicolumn{4}{|c|}{20,37} \\
\hline & \multicolumn{4}{|c|}{ Massa seca radicial (mg) } \\
\hline ANA & $20,76 \mathrm{aA}$ & $15,30 \mathrm{aA}$ & $26,02 \mathrm{aA}$ & $14,80 \mathrm{bA}$ \\
\hline AIB & $28,85 \mathrm{aA}$ & $30,51 \mathrm{aA}$ & $40,96 \mathrm{aA}$ & $42,98 \mathrm{aA}$ \\
\hline $\mathrm{CV}(\%)$ & \multicolumn{4}{|c|}{20,44} \\
\hline
\end{tabular}

Médias seguidas pela mesma letra maiúscula na linha e minúscula na coluna não diferem entre si pelo teste de Tukey ( $\mathrm{p} \leq 0,01$ ). Fonte: Elaboração dos autores.

Os resultados do comprimento de raízes (Tabela $2)$, não indicam diferenças estatísticas $(p \leq 0,01)$, quando se analisa o efeito isolado das concentrações de cada regulador vegetal utilizado (ANA e AIB). No entanto, verifica-se que a maior concentração de AIB (4000 mg L ${ }^{-1}$ ), foi a condição mais adequada para o crescimento das raízes. Resultados similares foram obtidos por Fischer et al. (2008), que obtiveram aumento no comprimento das raízes de mirtilo em relação ao aumento da concentração de AIB. Tais resultados são indicativos da eficiência do AIB para o aumento do volume radicial e comprimento de raízes, proporcionando às estacas, condições para a manutenção da sua viabilidade, uma vez que o desenvolvimento adequado do sistema radicial é um fator que influenciará diretamente no estabelecimento futuro da planta.
Na Tabela 2, observa-se que ambos reguladores não apresentaram diferenças significativas dentro das concentrações testadas. Entretanto, o uso do regulador vegetal AIB na concentração de 4000 $\mathrm{mg} \mathrm{L}^{-1}$ proporcionou maior massa seca radicial em relação à mesma concentração do ANA, indicando assim maior desempenho do regulador AIB em relação ao ANA, em promover o desenvolvimento do sistema radicial das estacas de melaleuca.

O comprimento das raízes em relação ao diâmetro (Tabela 3) confirma a maior eficiência do AIB em relação ao regulador ANA, pois observa-se que na concentração de $4000 \mathrm{mg} \mathrm{L}^{-1}$, o regulador vegetal ANA apresentou comprimento de raízes inferior ao apresentado pelo regulador AIB em todos os diâmetros avaliados. 
Tabela 3. Dados médios do comprimento em relação ao diâmetro radicial de estacas caulinares semi-lenhosas de Melaleuca alternifolia submetidas a diferentes reguladores vegetais e concentrações.

\begin{tabular}{|c|c|c|c|c|}
\hline \multirow{3}{*}{$\begin{array}{c}\text { Regulador } \\
\text { vegetal }\end{array}$} & \multicolumn{4}{|c|}{ Concentrações dos reguladores vegetais em $\mathrm{mg} \mathrm{L}^{-1}$} \\
\hline & 0 & 1000 & 2000 & 4000 \\
\hline & \multicolumn{4}{|c|}{ Comprimento radicial $(\mathrm{cm})$ em relação ao diâmetro $(0-0,5 \mathrm{~mm})$} \\
\hline ANA & $19,74 \mathrm{bA}$ & $15,60 \mathrm{aA}$ & $24,35 \mathrm{aA}$ & $7,88 \mathrm{bA}$ \\
\hline AIB & $44,40 \mathrm{aA}$ & $20,39 \mathrm{aA}$ & $35,66 \mathrm{aA}$ & $32,64 \mathrm{aA}$ \\
\hline \multirow[t]{2}{*}{ CV $(\%)$} & \multicolumn{4}{|c|}{23,81} \\
\hline & \multicolumn{4}{|c|}{ Comprimento radicial $(\mathrm{cm})$ em relação ao diâmetro $(0,5-1,0 \mathrm{~mm})$} \\
\hline ANA & $7,15 \mathrm{bA}$ & $5,47 \mathrm{aA}$ & $6,48 \mathrm{aA}$ & $3,45 \mathrm{bA}$ \\
\hline AIB & $13,39 \mathrm{aA}$ & $8,73 \mathrm{aA}$ & $9,87 \mathrm{aA}$ & $10,17 \mathrm{aA}$ \\
\hline \multirow[t]{2}{*}{$\mathrm{CV}(\%)$} & \multicolumn{4}{|c|}{18,01} \\
\hline & \multicolumn{4}{|c|}{ Comprimento radicial $(\mathrm{cm})$ em relação ao diâmetro $(1,0-1,5 \mathrm{~mm})$} \\
\hline ANA & $4,69 \mathrm{bA}$ & $4,19 \mathrm{aA}$ & $5,79 \mathrm{aA}$ & $3,22 \mathrm{bA}$ \\
\hline AIB & $9,1 \mathrm{aA}$ & $7,74 \mathrm{aA}$ & $8,65 \mathrm{aA}$ & $9,29 \mathrm{aA}$ \\
\hline \multirow[t]{2}{*}{$\mathrm{CV}(\%)$} & & & & \\
\hline & \multicolumn{4}{|c|}{ Comprimento radicial $(\mathrm{cm})$ em relação ao diâmetro $(1,5-2,0 \mathrm{~mm})$} \\
\hline ANA & $0,60 \mathrm{bA}$ & $0,86 \mathrm{bA}$ & $1,07 \mathrm{aA}$ & $0,52 \mathrm{bA}$ \\
\hline AIB & $1,34 \mathrm{aA}$ & $1,41 \mathrm{aA}$ & $1,45 \mathrm{aA}$ & $1,67 \mathrm{aA}$ \\
\hline \multirow[t]{2}{*}{$\mathrm{CV}(\%)$} & & & & \\
\hline & \multicolumn{4}{|c|}{ Comprimento radicial $(\mathrm{cm})$ em relação ao diâmetro $(2,0-2,5 \mathrm{~mm})$} \\
\hline ANA & $0,50 \mathrm{aA}$ & $0,67 \mathrm{aA}$ & $1,29 \mathrm{aA}$ & $0,52 \mathrm{bA}$ \\
\hline AIB & $0,99 \mathrm{aA}$ & $1,45 \mathrm{aA}$ & $1,92 \mathrm{aA}$ & $2,24 \mathrm{aA}$ \\
\hline \multirow[t]{2}{*}{$\mathrm{CV}(\%)$} & & & & \\
\hline & \multicolumn{4}{|c|}{ Comprimento radicial $(\mathrm{cm})$ em relação ao diâmetro $(2,5-3,0 \mathrm{~mm})$} \\
\hline ANA & $0,30 \mathrm{aA}$ & $0,11 \mathrm{aA}$ & $0,24 \mathrm{aA}$ & $0,19 \mathrm{bA}$ \\
\hline AIB & $0,28 \mathrm{aA}$ & $0,44 \mathrm{aA}$ & $0,64 \mathrm{aA}$ & $0,69 \mathrm{aA}$ \\
\hline CV $(\%)$ & & & & \\
\hline
\end{tabular}

Médias seguidas pela mesma letra maiúscula na linha e minúscula na coluna não diferem entre si pelo teste de Tukey ( $\leq \leq 0,01)$.

Fonte: Elaboração dos autores.

O maior comprimento de raízes de baixo diâmetro (0-0,5 mm), Tabela 3, para estacas tratadas com 4000 $\mathrm{mg} \mathrm{L} \mathrm{L}^{-1}$ de AIB, tornam essas estacas mais eficientes no processo de absorção de água e nutrientes nos estágios iniciais de desenvolvimento uma vez que as raízes de menor diâmetro são as principais responsáveis pela absorção de água e nutrientes do solo, obtendo o máximo de aproveitamento em sua rizosfera (VALCARCEL et al., 2007).

O desenvolvimento do sistema radicial é influenciado por diversos fatores, entre eles destacam-se as características químicas e físicas do substrato (HERTEL; LEUSCHENER;
HÖLSSCHER, 2003). Nesse sentido, o tipo de substrato utilizado pode apresentar interferência significativa no enraizamento das estacas. Conforme destacaram Zietemann e Roberto (2007), o substrato ideal é aquele que proporciona boa sustentação, nutrição das mudas, porosidade adequada para aeração, capacidade de drenagem e retenção adequada de água para hidratação das estacas. Deste modo, a realização de futuros trabalhos direcionados a obtenção de respostas ao comportamento do enraizamento de estacas de melaleuca mediante diferentes substratos tornam-se relevantes para a pesquisa. 


\section{Conclusões}

Pelos resultados obtidos concluiu-se que:

O regulador vegetal ANA na concentração de $4000 \mathrm{mg} \mathrm{L}^{-1}$ é fitotóxico para as estacas de Melaleuca alternifólia.

O uso de AIB na concentração de $4000 \mathrm{mg}$ $\mathrm{L}^{-1}$ proporciona maior porcentagem de estacas enraizadas e maior comprimento radicial.

\section{Referências}

ALTMAN, P. M. Australian tea tree oil - a natural antisseptic. Australian Journal of Biotechnology, Adelaide, v. 3, n. 4, p.247-248, 1989.

CARSON, C. F.; HAMMER, K. A.; RILEY, T. V. Melaleuca alternifolia (Tea Tree) oil: a review of antimicrobial and other medicinal properties. Clinical Microbiology Reviews, Washington, v. 19, n. 1, p. 50-62, 2006.

CENTELLAS, A. Q.; FORTES, G. R. L.; MÜLLER, N. T. G.; ZANOL, G. C.; FLORES, R.; GOTTINARI, R. A. Efeito de auxinas sintéticas no enraizamento in vitro da macieira. Pesquisa Agropecuária Brasileira, Brasília, v. 34, n. 2, p. 181-186, 1999.

COSTA JUNIOR, W. H.; SCARPARE FILHO, J. A.; BASTOS, D. C. Estiolamento da planta matriz e uso de ácido indolbutírico no enraizamento de estacas de goiabeiras. Revista Brasileira de Fruticultura, Cruz das Almas, v. 25, n. 2, p. 301-304, 2003.

COSTA, A. G.; STORCK, R. C.; ZUFFELLATORIBAS, K. C.; MOGOR, A. F. Diferentes concentrações de ácido indolbutírico no enraizamento de estacas de melaleuca. Horticultura Brasileira, Brasília, v. 25, n. 1, 2007. Suplemento.

DELGADO, J. P. M.; YUYAMA, K. Comprimento de estacas de camu-camu com ácido indolbutírico para a formação de mudas. Revista Brasileira de Fruticultura, Cruz das Almas, v. 32, n. 2, p. 522-526, 2010.

FACHINELLO, J. C.; HOFFMANN, A.; NACHTIGAL, J. C.; KERSTEN, E.; FORTES, G. R. L. Propagação de plantas frutíferas de clima temperado. 2. ed. Pelotas: UFPel, 1995. $178 \mathrm{p}$.

FISCHER, D. L. O.; FACHINELLO, J. C.; ANTUNES, L. E. C.; TOMAZ, Z. F. P.; GIACOBBO, C. L. Efeito do ácido indolbutírico e da cultivar no enraizamento de estacas lenhosas de mirtilo. Revista Brasileira de Fruticultura, Cruz das Almas, v. 30, n. 2, p. 285-289, 2008.

FRANZON, R.; ANTUNES, L. E. C.; ROSEIRA, M. C. B. Efeito do AIB e de diferentes tipos de estaca na propagação vegetativa da goiabeira-serrana (Acca sellowiana Berg). Revista Brasileira de Agrociência, Jaboticabal, v. 10, n. 4, p. 515-518, 2004.

HARTMANN, H. T.; KESTER, D. E.; DAVIES JUNIOR, F. T.; GENEVE, R. L. Plant propagation: principles e practices. 7. ed. New Jersey: Prentice Hall, 2002. 880 p.

HERTEL, D.; LEUSCHENER, C.; HÖLSSCHER, D. Size and structure of fine root systems in old-growth and secondary tropical montane forest (Costa Rica). Biotropica, Lawrence, v. 35, n. 2, p. 143-153, 2003.

LEE, L. S.; BROOKS, L. O.; HOMMER, L. E.; ROSSETTO, M.; HENRY, R. J.; BAVERSTOCK, P. R. Geographic variation in the essential oils and morphology of natural populations of Melaleuca alternifolia (Myrtaceae). Biochemical Systematics and Ecology, Oxford, v. 30, n. 4, p. 343-360, 2002.

OLIVEIRA, Y.; SILVA, A. L. L.; PINTO, F.; QUOIRIN, M.; BIASI, L. A. Comprimento das estacas no enraizamento de melaleuca. Scientia Agrária, Curitiba, v. 9, n. 3, p. 415-418, 2008.

RUSSEL, M.; SOUTHWELL, I. Monoterpenoid accumulation in Melaleuca altenifolia seedlings. Phytochemistry, Oxford, v. 59, n. 7, p. 709-716, 2002.

SILVA, F. A. Z. Sistema de assistência estatística - ASSISTAT versão 7.6 beta. Campina Grande: Departamento de Engenharia Agrícola (DEAG)/CTRN/ Universidade Federal, 2008. Disponível em: <http:// www.assistat.com/>. Acesso em: 21 dez. 2010.

SILVA, F. V. C.; CASTRO, A. M.; CHAGAS, E. A.; PESSONI, L. A. Propagação vegetativa de camu-camu por estaquia: efeito de fitorreguladores e substratos. Revista AgroAmbiente, Boa Vista, v. 3, n. 2, p. 92-98, 2009.

SOUZA, V. C.; LORENZI, H. Botânica sistemática. Guia ilustrado para identificação das famílias de Angiospermas da flora brasileira, baseado em APGII. 2. ed. Nova Odessa: Instituto Plantarum, 2005. 724 p.

VALCARCEL, R.; VALENTE, F. D. W.; MOROKAWA, M. J.; CUNHA NETO, F. V.; PEREIRA, C. R. Avaliação da biomassa de raízes finas em área de empréstimo submetida a diferentes composições de espécies. Revista Árvore, Viçosa, v. 31, n. 5, p. 923-930, 2007. 
VASCONCElOS, J. M.; LIMA, I. A. C.; VIEIRA, T. R.; BARBOSA, L. C. A.; MALTHA, C. CHOCOROSQUI, A. F.; TEIXEIRA, R. B.; RAPOSO, A. Efeitos dos reguladores de crescimento AIA, AIB e ANA no enraizamento in vitro de Uncaria tomentosa. In: CONGRESSO BRASILEIRO DE FISIOLOGIA VEGETAL, 12., 2010, Fortaleza. Resumos... Rio Claro: Sociedade Brasileira de Fisiologia Vegetal, 2010. Disponível em: <http://www.sbfv.org.br/congresso2009 /trabalhos/autor/crescimento_e_desenvolvimento/175. pdf. $>$. Acesso em: 01 ago. 2010.

R. A. Constituintes químicos de Melaleuca alternifólia (Myrtaceae). Química Nova, Brasília, v. 27, n. 4, p. 536$539,2004$.

WAREING, P. F.; PHILLIPS, I. D. J. Growth and differentiation in plants. 3. ed. Oxford, England: Pergamon Press, 1981. 343 p.

ZIETEMANN, C.; ROBERTO, S. R. Produção de mudas de goiabeira (Psidium guajanva L.) em diferentes substratos. Revista Brasileira de Fruticultura, Cruz das Almas, v. 29, n. 1, p. 137-142, 2007. 
